\title{
Transferência de Blastocisto após Descongelamento de Embriōes em Mórula Resultando em Gestação Gemelar: Relato de Caso
}

\author{
Twin Pregnancy after Thawing of Morula Embryos and Blastocyst Transfer: Case Report \\ Luiz Eduardo T. Albuquerque ${ }^{1}$, Maria Cecília R. Maciel², Paulo C. Matheus², \\ Edir Catafesta ${ }^{3}$, Dirceu Henrique Mendes Pereira ${ }^{1}$ \\ RESUMO
}

\begin{abstract}
A criopreservação de embriões em estágios mais tardios do desenvolvimento parece apresentar resultados satisfatórios. Com o objetivo de melhor testar a sobrevivência e o desenvolvimento de embriões, os mesmos foram criopreservados e descongelados em estadio de mórula ou blastocisto e deixados em cultura para que pudesse ser avaliada sua evolução natural. Dos 2 blastocistos e 5 mórulas congelados, 4 mórulas sobreviveram ao descongelamento, tendo sido transferidas em estadio de blastocisto, 24 horas depois. A transferência, realizada em paciente jovem, segundo casamento de homem vasectomizado há dez anos, resultou em gestação gemelar. O descongelamento de embriões em estadio de mórula e a observação in vitro da retomada de seu desenvolvimento até o estadio de blastocisto fornecem um parâmetro adicional na avaliação da qualidade do embrião e, provavelmente, melhore as taxas de gravidez.
\end{abstract}

PALAVRAS-CHAVE: Infertilidade. Fertilização in vitro. Criopreservação de embriões.

\section{Introdução}

O advento da co-cultura de células somáticas e, mais recentemente, o desenvolvimento e introdução de meios de cultura seqüenciais propiciaram a evolução dos embriões até o estádio de blastocisto ${ }^{1,2,3}$. A literatura mostra um aumento das taxas de gravidez com a transferência tardia (em blastocisto), além de referir também resultados adequados quanto à sobrevivência de embriões criopreservados em fase de blastocisto ${ }^{4,5}$.

Com a finalidade de testar a sobrevivência dos embriões em estádio tardio após o descongelamento, estabelecemos um protocolo que consiste em congelá-los em fase de mórula; por ocasião da transferência os embriões são descongelados e colocados em meio de cultura por 24 horas. A observação de blastocistos demonstra

${ }^{1}$ Programa de Reprodução Assistida; ${ }^{2}$ Laboratório de Fertilização in vitro; ${ }^{3}$ Laboratório de Andrologia, Profert, São Paulo, SP.

Correspondência:

Luiz Eduardo Albuquerque

Av. Indianópolis, 395

04063-020 - São Paulo - SP

Fax: (11) 539-1055

e-mail: profert@profert.com.br adequada sobrevivência e prognóstico favorável de gravidez.

\section{Relato do Caso}

DGC, 32 anos, esterilidade primária por fator masculino; CMM, o marido, 38 anos, três filhos do primeiro casamento, vasectomizado há dez anos (dezembro de 1988). Foi indicada como tratamento para o casal a fertilização in vitro (FIV) com injeção intracitoplasmática de espermatozóides (ICSI) obtidos por punção aspirativa de epidídimo (PESA)

Para a indução da ovulação foi utilizado o protocolo longo, com administração de $0,15 \mathrm{ml}$ de análogo agonista do GnRH (Lupron - 2,8 $\mathrm{ml}$ - Abbott) a partir do $20^{\circ}$ dia do ciclo anterior. A indução da ovulação foi realizada com FSHr (Puregon Organon), administrado a partir do $2^{\circ}$ dia do ciclo menstrual na dose de 200 UI por 4 dias, tendo sido diminuída no $5^{\circ}$ dia de indução para $150 \mathrm{Ul}$, no $6^{\circ}$ dia para $100 \mathrm{UI}$, dose que foi mantida até o $9^{\circ}$ dia de indução; no $10^{\circ}$ dia foram administradas 10.000 UI de hCG (Profasi - Serono).

A aspiração folicular ocorreu aproxi- 
madamente 35 horas após a administração do hCG, tendo sido recuperados 24 oócitos dos 29 folículos puncionados; 23 dos 24 (95,8\%) oócitos aspirados estavam em metáfase II (MII) e apenas um oócito era imaturo, em metáfase I (MI).

Foram micromanipulados e submetidos à ICSI os 23 MII e, 18 horas após a injeção, 16 (70\%) deles estavam fertilizados, podendo ser observados os dois pró-núcleos (2PN). Estes embriões, cultivados em meio de cultura apropriado (HTF medium - Irvine) por 72 horas ( $3^{\circ}$ dia pós-aspiração folicular), foram então transferidos para outro meio de cultura, um meio de cultura prolongada (Blastocyst Medium - Irvine) cujas características bioquímicas permitem o cultivo de pré-embriões por 120 horas $\left(5^{\circ}\right.$ dia pós-aspiração folicular), quando atingem o estádio de blastocisto. Dos 16 oócitos fertilizados, $5(31,2 \%)$ evoluíram para blastocisto e $6(37,5 \%)$ para mórula; 3 blastocistos foram transferidos e o restante foi criopreservado. A técnica utilizada para a criopreservação dos embriões foi similar à técnica descrita por Lassalle et al. ${ }^{6}$, sendo utilizado como crioprotetor 1,2 propanodiol (PROH - Sigma P - 1009) e sacarose (Sigma S - 1888).

Preparam-se três soluções: I- meio de cultura (DPBS - Gibco BRL cat. N ${ }^{\circ} 14040-141$ ) mais $20 \%$ de substituto de soro (SSS - Irvine Scientific - cat. 99193); II- solução de 1,5 M PROH em PBS + $20 \%$ SSS; III- solução de 1,5 M PROH mais $0,1 \mathrm{M}$ sacarose em PBS $+20 \%$ SSS. As soluções devem estar à temperatura ambiente para o congelamento. Os embriões a serem congelados são transferidos do meio de cultura a $37^{\circ} \mathrm{C}$ para a solução I, na qual são lavados rapidamente, tempo suficiente para observar a morfologia e o número de células, logo após são colocados na solução II por 10 minutos e posteriormente na solução III por aproximadamente 1 minuto. São então colocados em palhetas identificadas, seladas e levadas ao congelador de embriões (Planer Products Ltd., Sundbury-on-Thames, UK), onde passam por um processo de congelamento lento préprogramado em três rampas (etapas): temperatura inicial $16^{\circ} \mathrm{C}$, rampa 1 , sob uma velocidade de $-2^{\circ} \mathrm{C} /$ min até $-8^{\circ} \mathrm{C}$, neste momento foi feito o seeding manual, rampa 2 , sob uma velocidade de $-0,3^{\circ} \mathrm{C} /$ min até $-30^{\circ} \mathrm{C}$ e rampa 3 , com uma velocidade de $50^{\circ} \mathrm{C} / \mathrm{min}$ até $-150^{\circ} \mathrm{C}$. Após este processo as palhetas são armazenadas em container de nitrogênio líquido apropriado a uma temperatura de $-196^{\circ} \mathrm{C}$.

Para manutenção da fase lútea foi utilizada progesterona micronizada via vaginal, $600 \mathrm{mg} / \mathrm{dia}$ (Utrogestran - Bensis Iscovesco); o $\beta$ hCG quantitativo do primeiro controle foi negativo.

Sete meses depois foi realizado novo ciclo para transferência dos embriões que haviam sido criopreservados. O ciclo foi iniciado com administração do análogo agonista do GnRH de depósito (Zoladex - Zeneca) no segundo dia do ciclo menstrual. O preparo de endométrio foi iniciado após $11 \mathrm{dias}$, com o uso de $1 \mathrm{mg} /$ dia de estradiol (Sandrena - Organon), dose que foi aumentada gradualmente até $6 \mathrm{mg} /$ dia. Quando o acompanhamento ultra-sonográfico indicou a presença de endométrio de $8 \mathrm{~mm}$ de diâmetro, a dose de estradiol foi reduzida para $4 \mathrm{mg} /$ dia e iniciada a administração de $600 \mathrm{mg} /$ dia de progesterona micronizada via vaginal (Utrogestan - Bensis Iscovesco); a transferência foi realizada três dias após o início da progesterona.

Um dia antes da transferência foram descongelados 2 blastocistos e 5 mórulas, utilizando-se a técnica de descongelamento rápido descrita por Lassalle et al. ${ }^{6}$. Esta técnica consiste em preparar quatro soluções: I- 1,0 M PROH + 0,2 $\mathrm{M}$ sacarose; II- 0,5 M PROH + 0,2 M sacarose; III$0,2 \mathrm{M}$ sacarose; IV- DPBS $+20 \%$ SSS. As palhetas são retiradas do container de nitrogênio liquido e deixadas 40 segundos em temperatura ambiente, mais 40 segundos a $30^{\circ} \mathrm{C}$, terminando-se o processo com a retirada das substâncias crioprotetoras utilizando-se soluções de descongelamento. Foram colocadas 5 minutos nas soluções I e II e 10 minutos nas soluções III e IV, respectivamente. Quatro mórulas sobreviveram ao descongelamento e, após 24 horas em meio de cultivo, haviam prosseguido o desenvolvimento e atingido o estágio de blastocisto, tendo sido transferidas.

Onze dias após a transferência o $\beta$ hCG quantitativo foi positivo $(749 \mathrm{mUI} / \mathrm{ml})$; cinco dias depois aferia $4260 \mathrm{mUI} / \mathrm{ml}$, o estradiol $433 \mathrm{pg} / \mathrm{ml}$ e a progesterona $10 \mathrm{ng} / \mathrm{ml}$. O terceiro controle, 7 dias depois, revelou $\beta$ hCG de $49.100 \mathrm{mUI} / \mathrm{ml}$, estradiol de $1182 \mathrm{pg} / \mathrm{ml}$ e progesterona de $15,5 \mathrm{ng} /$ $\mathrm{ml}$. Uma semana depois foi realizado o $4^{\circ}$ controle, um ultra-som endovaginal que evidenciou gestação tópica gemelar, com embriões presentes e com batimentos cardíacos; a idade gestacional do primeiro embrião foi estimada em 6 semanas e 5 dias e do segundo em 6 semanas e 1 dia. O $\beta$ hCG aferia $155.900 \mathrm{mUI} / \mathrm{ml}$, o estradiol 976 pg/ $\mathrm{ml}$ e a progesterona $13 \mathrm{ng} / \mathrm{ml}$.

O último controle antes deste relato foi realizado por ultra-sonografia endovaginal em gestação gemelar de 10 semanas e 4 dias, compativel com a idade gestacional esperada pelo tempo de transferência.

\section{Discussão}

Nos programas de reprodução assistida que realizam a transferência embrionária no $2^{\circ}$ (D2) ou $3^{\circ}$ (D3) dia, a seleção dos embriões segue o critério morfológico clássico. No entanto, sabe-se 
que apenas um terço desses embriões conseguirá se desenvolver até o estadio de blastocisto ${ }^{3,7}$ e nem sempre o embrião morfologicamente mais adequado será aquele que logrará êxito no desenvolvimento. Desta forma, a escolha de embriões para a transferência em D2 ou D3 é aleatória e os índices de gestação não ultrapassam $30 \%$ levando muitos centros a transferir mais embriões, o que, por sua vez, acarreta aumento do número de gestações múltiplas.

Mais próximo do que acontece naturalmente no organismo, a transferência de blastocisto no $5^{\circ}$ dia somente tornou-se possivel com o desenvolvimento de meios de cultivo seqüenciais, que respeitam a mudança no metabolismo embrionário nesse momento do desenvolvimento. De fato a literatura chega a referir taxas de implantação de até $60 \%$ com a transferência de blastocistos, possibilitando uma diminuição no número de embriões transferidos e, conseqüentemente, de gestações múltiplas.

E embora somente metade dos embriões consiga atingir o estádio de blastocisto, quando um casal apresenta um número grande de embriões em D2 ou D3 as chances de se obterem blastocistos em D5 são grandes e os centros de medicina reprodutiva que adotarem a transferência tardia certamente necessitarão de um programa de congelamento de embriões em mórula ou blastocisto.

Alguns grupos têm mostrado bons resultados com o congelamento e descongelamento de blastocistos ${ }^{4,5,8,9}$, e embriões congelados neste estádio parecem ter melhores chances de sobrevivência que aqueles criopreservados em estágios iniciais de clivagem ${ }^{8}$.

O presente relato sugere a criopreservação em estadio de mórula para que seja possivel a escolha do melhor embrião com base em sua retomada do desenvolvimento e capacidade de atingir o estádio de blastocisto em cultura e pósdescongelamento. É necessária, no entanto, a consciência de que estudos prospectivos e randomizados serão necessários para confirmação dessa observação inicial.

\section{SUMMARY}

The cryopreservation of embryos in late developing stages seems to present satisfactory results. With the purpose of better testing the embryos' survival, they were cryopreserved in the morula or blastocyst stage, thawed and left in culture for 24 hours so that their natural evolution could be observed.
Amongst the frozen 2 blastocysts and 5 morulas, 4 morulas survived the thawing process, being transferred as blastocysts 24 hours later. The transfer was performed in a young patient, second marriage of a ten-year vasectomized man and resulted in twin pregnancy. Thawing morula embryos and the in vitro observation of their development resumption until the blastocyst stage give us an additional parameter in the quality evaluation of the embryo and probably an improvement in pregnancy rates.

KEY WORDS: Infertility. "In vitro" fertilization. Embryo cryopreservation.

\section{Referências}

1. Gardner DK, Lane M. Culture and selection of viable blastocysts: a feasible proportion for human IVF? Hum Reprod Update 1997; 3:367-82.

2. Jones GM, Trounson AO, Gardner DK, Kausche A, Lolatgis N, Wood C. Evolution of a culture protocol for successful blastocyst development and pregnancy. Hum Reprod 1998; 13:169-77.

3. Menezo Y, Nicollet B, Herbaut N, André D. Freezing cocultured human blastocysts. Fertil Steril 1992; 58:977-80.

4. Cohen J, Simons RS, Fehilly CB, Edwards RG. Factors affecting survival and implantation of cryopreserved human embryos. J In Vitro Fert Embryo Transf 1986;3:46-52.

5. Hartshorne GM, Elder K, Crow J, Dyson H, Edwards RG. The influence of in vitro development upon post-thaw survival and implantation of cryopreserved human blastocyst. Hum Reprod 1991; 6:136-41.

6. Lassalle B, Testart J, Renard JP. Human embryo features that influence the success of cryopreservation with use of 1,2 propanediol. Fertil Steril 1985; 44:645-51.

7. Lopata A, Hay DL. The surplus human embryo: its potential for growth, blastulation, hatching and human chorionic gonadotropin production in culture. Fertil Steril 1989;51:984-91.

8. Fehilly CB, Cohen J, Simons RF, Fishel SB, Edwards RG. Cryopreservation of cleaving embryos and expanded blastocysts in the human: a comparative study. Fertil Steril 1985;44:638-44.

9. Cohen J, Simons RF, Edwards RG, Fehilly CB, Fishel SB. Pregnancies following the frozen storage of expanding human blastocysts. J In Vitro Fert Embryo Transf 1985;2:59-64. 